\title{
Rwanda Cricket Stadium: Seismically Stabilised Tile Vaults
}

\author{
Michael RAMAGE*,a, Timothy J. HALL ${ }^{\mathrm{a}}$, Ana GATÓO ${ }^{\mathrm{a}}$, M. Wesam Al ASALI \\ *Department of Architecture \\ Cambridge University \\ Cambridge CB2 1PX UK \\ mhr29@cam.ac.uk \\ ${ }^{a}$ Light Earth Designs LLP
}

\begin{abstract}
The Rwanda Cricket Stadium, completed in 2017, uses compressed soil-cement tiles, thin-tile vaulting, and geogrid reinforcement for seismic stabilisation in Kigali's moderate risk earthquake zone. The vaults follow the natural resolution of forces toward the ground, closely mimicking the parabolic geometry of a bouncing ball and evoking the cherished hilly topography of Rwanda. The masonry vaults in compression allow the use of geogrid embedded within the mortar layers, adding global ductile behaviour to the thin shell composite of low strength tiles. Structural analysis is based on thrust lines, with additional envelope for the thrust lines to leave the profile of the masonry computed from the tensile capacity added by the geogrid (Ramage and Dejong [1]). Construction follows traditional thin-tile techniques adapted for new environments and uses compressed earth tiles as pioneered at the Mapungubwe Interpretive Centre in South Africa (Ramage et al. [2]). Here, the two approaches are combined in a permanent structure, with the largest vault spanning $16 \mathrm{~m}$ with a rise of $8 \mathrm{~m}$. The Rwanda Cricket Stadium is a fusion of advanced structural analysis and architectural design with labour intensive, locally-sourced material production offering a much-needed solution to building sustainably in the developing world. Employing air-dried, hand-pressed soil tiles, produced using local labour, this method of construction has proved to be innovative, cost effective and beautiful.
\end{abstract}

Keywords: structural design, thin-tile vaults, masonry, form-finding, earthquake design, compressed-earth blocks.

\section{Introduction}

The Rwanda Cricket Stadium in Kigali (Figure 1) is formed of three parabolic vaults following the natural resolution of forces, designed to be in compression under static loads. Light Earth Designs undertook the project for the Rwanda Cricket Stadium Foundation and the Cricket Builds Hope Foundation, empowering the development of the local economy of Rwanda by using labour-intensive technologies and local materials.

The primary enclosure of the building, the vaults, adapt Mediterranean thin-tile masonry to a moderate risk earthquake zone by employing geogrid between layers. The vaults are made using compressed soilcement tiles made from site-excavated earth.

Simple, efficient concrete tables form more enclosed spaces - service areas, changing rooms, an office and a restaurant (Figure 2). Low-carbon, agro-waste-fired, locally-made bricks are used to define edges and spaces. Clay tiles, broken granite and slate are used for flooring. Plywood rectangles from tilemaking are reused as countertops, while material from the vault guidework is made into joinery and doors, ensuring that a maximum of potential waste goes into primary production. The $650 \mathrm{~m} 2$ building was constructed in 6 months with a total cost of $\sim £ 500,000$. 


\section{Background}

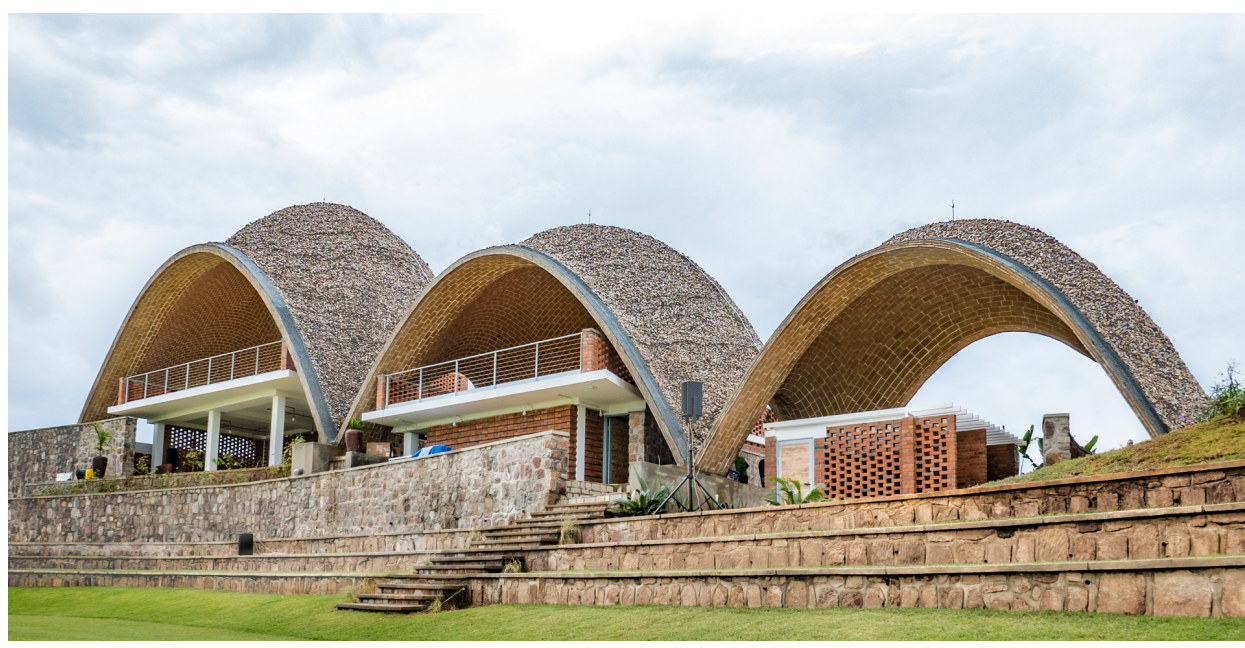

Figure 1 Rwanda Cricket Stadium, Kigali

The Rwanda Cricket Stadium extends projects by Light Earth Designs and implements experiments and research conducted at Cambridge University.

Thin-tile vaults are distinguished by rapid construction and structural efficiency. The vault does not need formwork for construction, only minimal guidework to show the curvature of the structure while being built. This is possible because the tiles are bonded on the thin edges with fast setting gypsum mortar on the first layer, setting in a few seconds. Subsequent layers are set in bricklayers' mortar.

Although not in common use, thin-tile vaulting has been used for hundreds of years throughout the Mediterranean. Catalan Modernisme, including architectural virtuosos like Antoni Gaudí, brought the technique to its zenith. Rafael Guastavino, a Valencian architect, exported the technique to the United States where father and son built more than a thousand buildings, including the Boston Public Library and New York City's Grand Central Terminal (Ochsendorf [3]).

The technique had always used fired clay tiles until 2009, when the Mapungubwe Interpretative Centre in South Africa was built with local materials and employing local unskilled workers in a Poverty Relief Program. These limitations led to the design of unreinforced thin-tile vaults made from soil-cement tiles from site-excavated earth and topped with stone for additional weight and stability (Ramage et al. [2]).

\section{Structural Design}

Creative use of structural form makes thin-tile vaults efficient. When vaults are designed following the thrust line, minimal material is needed for the form, which is parabolic under a discrete number of

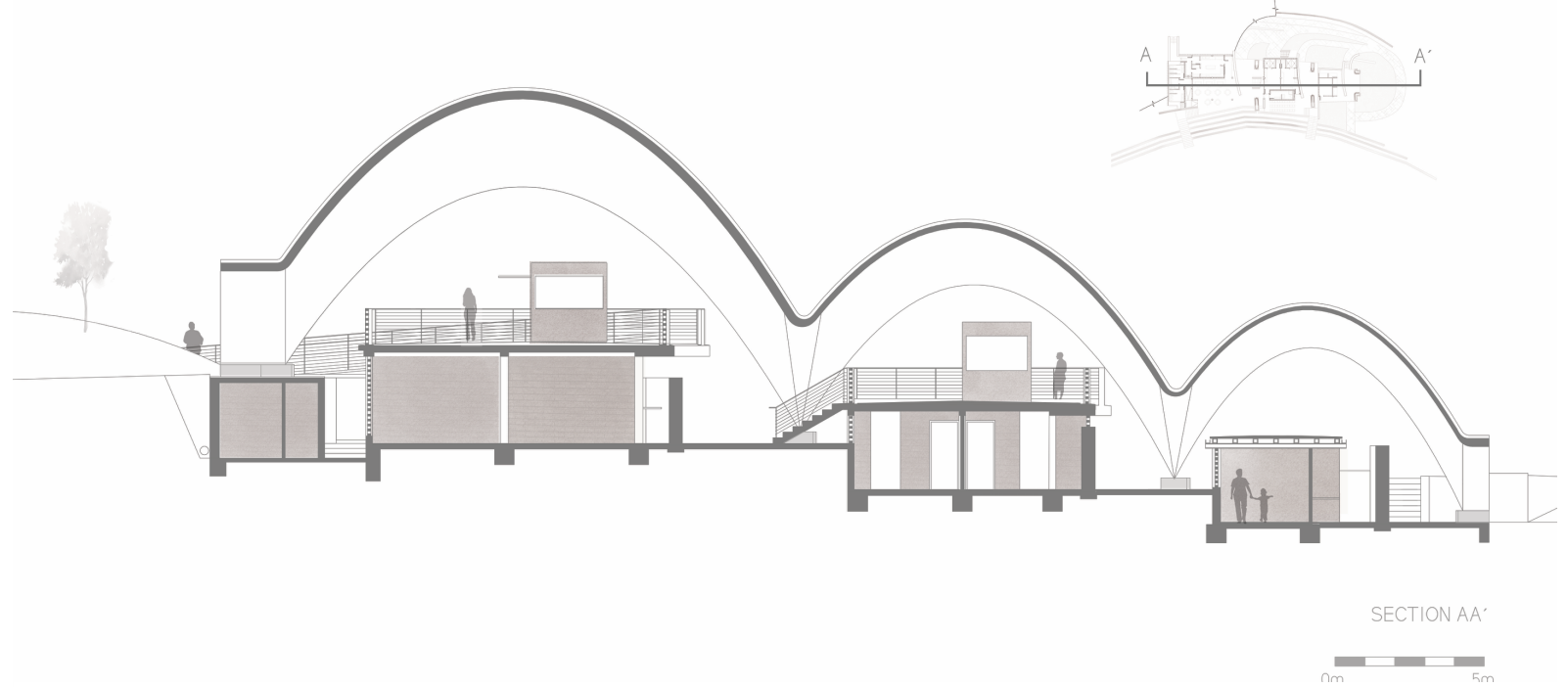

Figure 2 Rwanda Cricket Stadium Section 
uniform loads. Unreinforced masonry vaults are not typically considered suitable for seismic design. This limitation led to incorporating triaxial geogrid, in the form of Tensar TX [4], typically used for road beds, as a lightweight reinforcing material to thin-tile vaults to control dynamic lateral loads without compromising the lifespan of the structure (Ramage and Dejong [1]). The 4mm-thick polypropylene geogrid is formed of triangular elements connected at nodes (Figure 3).

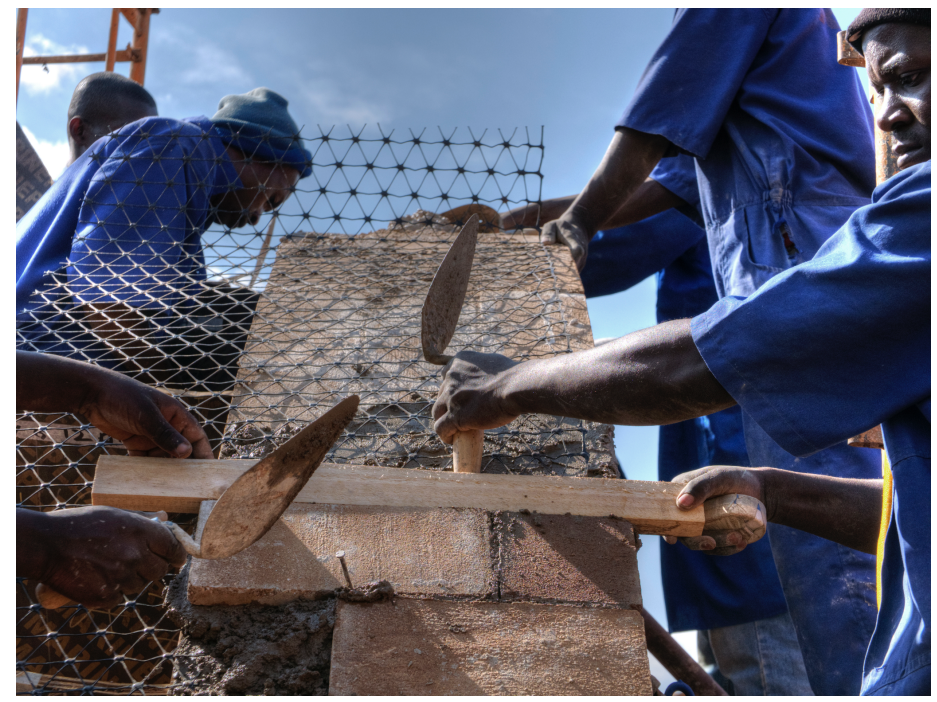

Figure 3 Embedding geogrid in the edge arches

Static panel bending tests and dynamic shake table tests were conducted at Cambridge University showing that ductility was significantly increased even with minimal reinforcement and, with increasing reinforcement, the bending capacity would also increase (Dejong et al. [5]). Incorporating geogrid allows us to calculate a performance envelope where the line of thrust can safely deviate from the geometry [1]. The studies suggested the possibility for safe use of geogrid for low to moderate seismic areas in combination with appropriate design procedures and the benefits of double curvature vaults.

Dejong et al. [5] compared empirical panel tests with an analytical model of thin-tile masonry with embedded geogrid. The panels were made and analysed using the geometry shown in Figure 4. The $650 \mathrm{~mm} \times 215 \mathrm{~mm} \times 80 \mathrm{~mm}$ panels were tested in displacement-controlled three-point bending over a span of $520 \mathrm{~mm}$. After initial cracking at about $1 \mathrm{~mm}$ of displacement, the unreinforced masonry panel had little residual capacity, whereas the reinforced panel retained some capacity due to the geogrid. The reinforced panels demonstrated roughly $80 \%$ load-carrying capacity through vertical displacement of $10-20 \mathrm{~mm}$, until tensile failure of individual elements in the geogrid.

(a)

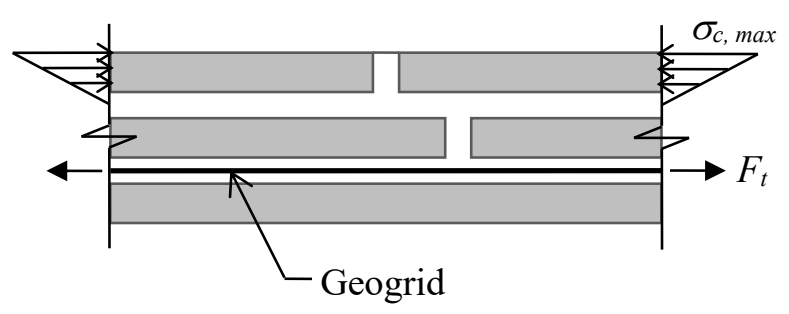

(b)

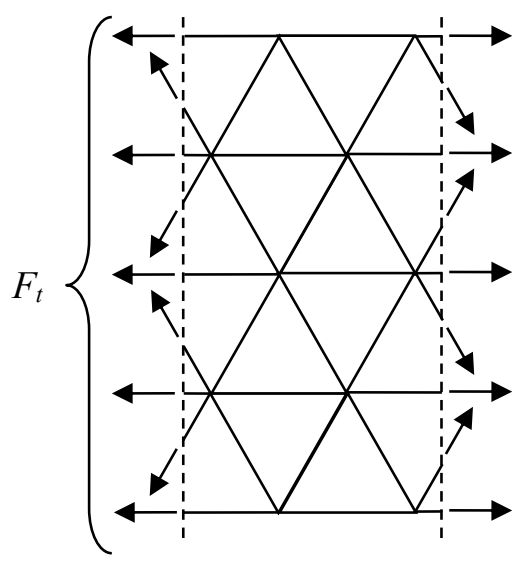

Figure 4 (a) Section of a three-layer geogrid-reinforced vault under a constant sagging moment. (b) Representative plan view of the forces on the geogrid reinforcing in (a). From Dejong et al. [5]

The analytical model of Dejong et al. [5] assumes a triangular compressive stress distribution (Figure 4 a), with tensile capacity $\mathrm{F}_{\mathrm{t}}$ ( Figure $4 \mathrm{a}, \mathrm{b}$ ) calculated from the tensile capacity tested in an individual 
element. Combining this analysis with stress relief into adjacent elements of the geogrid due to spalling seen during the test and material properties, Dejong et al. were able to get a simulation that closely matched the experimental results (Figure 5).

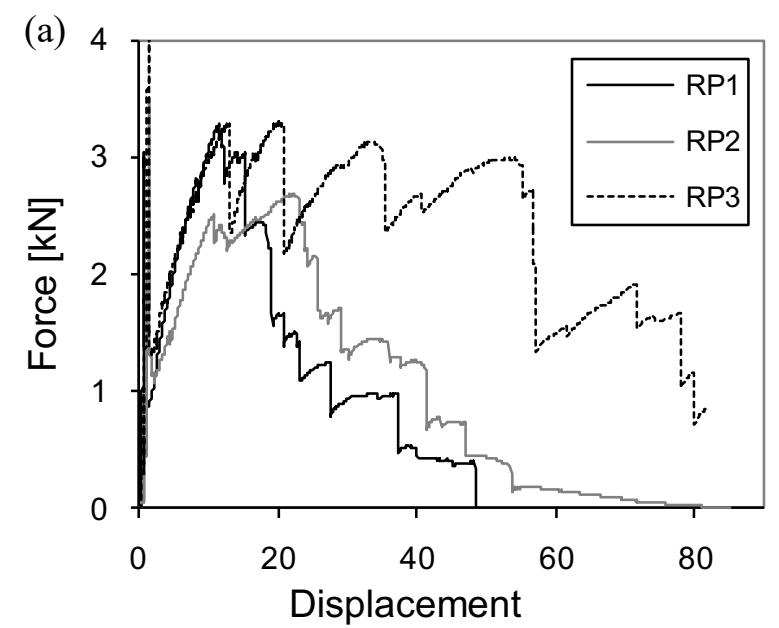

(b)

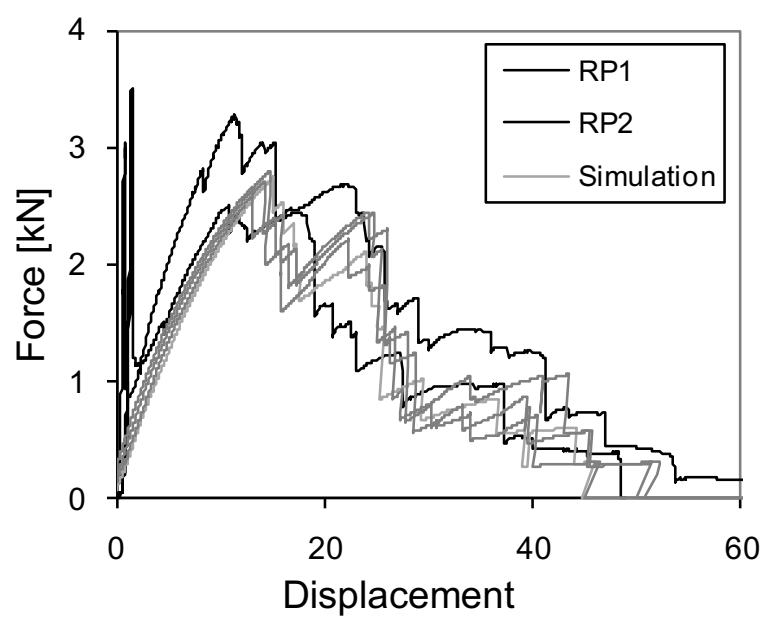

Figure 5 : Load-displacement response of (a) the geogrid-reinforced panels, and (b) comparison to simulation results. From Dejong et al. [5]

(a)

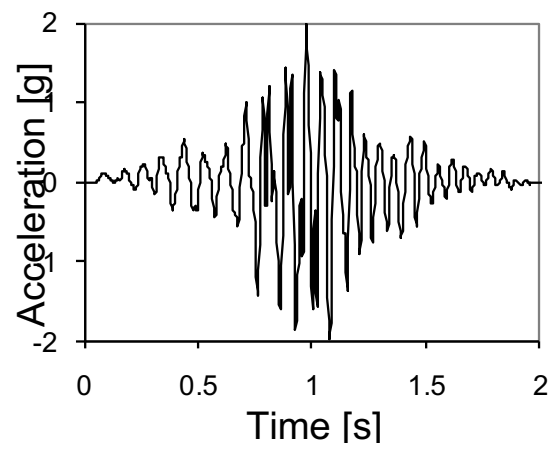

(b)

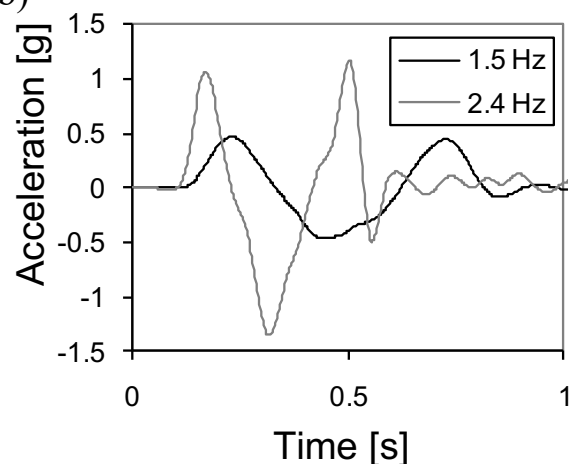

(c)

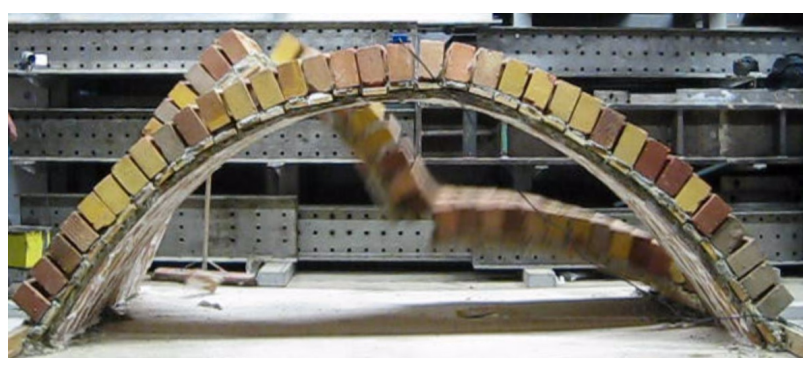

(d)

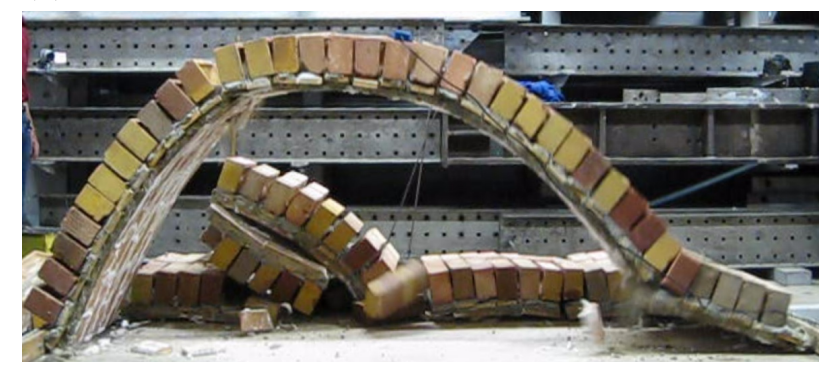

Figure 6 The four-hinge failure mechanisms formed by the (c) unreinforced vault and (d) reinforced vault due to the impulse ground motion accelerations in ( $a$ and $b$ ). From Dejong et al. [5]

Dejong et al. used shake table tests to further explore the potential for geogrid to increase the capacity of thin tile vaults. Two $2 \mathrm{~m}$ span parabolic barrel vaults, one with and one without geogrid reinforcing, were subjected to increasing lateral accelerations. The vaults were scaled by increasing their density to represent geometrically similar spans of $5 \mathrm{~m}$. Initially the vaults were subjected to $15 \mathrm{~Hz}$ harmonic excitation (Figure 6a), which caused some cracking but no catastrophic failure in either vault. Next, they were subjected to a series of single period cosine ground motion pulses (amplitude $=+-4 \mathrm{~cm}$, total travel $=8 \mathrm{~cm}$ out and back) of increasing frequency until collapse. At $1.5 \mathrm{~Hz}$ (theoretical acceleration $a_{t}=0.36$ $\mathrm{g}$, Figure $6 \mathrm{~b}$ ), the unreinforced vault formed four hinges and collapsed (Figure $6 \mathrm{c}$ ). The reinforced vault exhibited minor hinging where cracks had formed previously. Over eight more impulses the reinforced 
vault should increasing hinging, with eventual collapse at $2.4 \mathrm{~Hz}\left(a_{t}=0.93 \mathrm{~g}\right.$, Figure $\left.5 \mathrm{~b}\right)$, demonstrating significant increased capacity due to the geogrid reinforcing. [5]

As reported in Ramage and Dejong, laboratory study was combined with two temporary pavilions, one in San Francisco and one in London, which were built following the traditional method of thin tile vaults but with the addition of geogrid and corresponding calculations. Both pavilions were demolished afterwards, qualitatively highlighting the structural capacity under dynamic loads and again demonstrating an appropriate technology for use in low to moderate seismic risk areas (Ramage and Dejong [1]).

In static loading conditions, the geometry and the line of thrust coincide, but in earthquake loading, the line of thrust deviates from the geometry and the tensile capacity of the geogrid imparts limited bending capacity in the composite material, allowing the structure to stand. [1] The low stiffness of the geogrid ensures that it takes no stress until hinges form in the masonry.

As outlined in Ramage and Dejong, three equations arise from the geometry of the masonry, geogrid, and forces (Figures 7 and 8). Eq 1 governs the compression only case, with Eq 2 used to ensure that the maximum compressive strength of the masonry isn't exceeded. Eq 3 incorporates the geogrid in cases where the vault goes into tension under certain loading conditions [1].

$$
\delta=\frac{b t^{2}}{6 F} \sigma_{t, \max }-\frac{t}{3}(1)
$$

where $b$ is the width of the slice being analysed, $t$ is the thickness of the material, $F$ is the thrust and $\sigma_{t, \max }$ is the maximum tensile stress in the masonry.

$$
\begin{gathered}
\delta<\frac{b t^{2}}{6 F} \sigma_{c, \max }-\frac{2}{3} t \\
\delta=\frac{T h}{F}-\frac{2}{3} \frac{(T+F)^{2}}{F \sigma_{c, \max } b}
\end{gathered}
$$

where $T$ is the total tensile capacity of the geogrid, $h$ is the depth to the geogrid, $F$ is the thrust, $\sigma_{c, \max }$ is the maximum compressive stress in the masonry, and $b$ is the width of the slice.

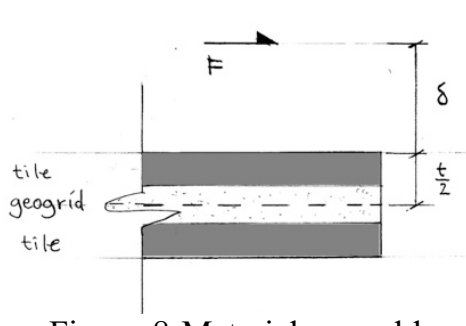

Figure 8 Material assembly and force geometry for the compression-only solution. From Ramage and Dejong [1]

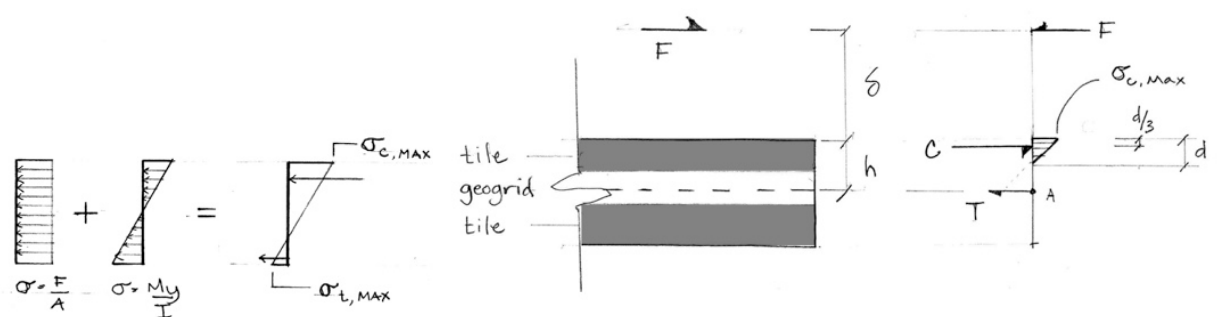

Figure 8 Force geometry for tension solution with geotextile engaged. Moment taken about point A. From Ramage and Dejong [1]

The Rwanda Cricket Stadium, located in the moderate risk seismic zone of Kigali, is the first permanent building to incorporate both achievements: the use of cement-stabilized tiles made from site-excavated soil and the use of geogrid to improve its behaviour in asymmetrical and dynamic load cases.

To analyse the vaults' structure, we used graphic statics, a method to design and analyse structures based on drawn vectors and geometry (Allen and Zalewski [6]). Graphic statics' advantage lies in the relationship between form and forces (Van Mele et al. [7]). It uses two complementary, reciprocal diagrams: a form diagram that represents the geometry of the structure and a force diagram which shows the equilibrium of the internal and external forces, resolved as the line of thrust through the structure (Block et al. [8]). 
The analysis of load cases was done with Geogebra [9] applying a 2D slicing technique, where the structure is sliced through a series of load paths turning the vault into different arches. As each vault is symmetrical, we analysed half of the structure. We sliced each half vault with 3 cuts and made a cut per each of the four cross section arches. We then analysed each cut for the three possible scenarios: static loads, wind loads and earthquake loads (Figure 9). Where the line of thrust exits the geometry, we used the perpendicular distance of deviation from the vault surface and equations (1-3, above) from Ramage and Dejong [1], modified to account for the total vault thickness, to ensure stability.

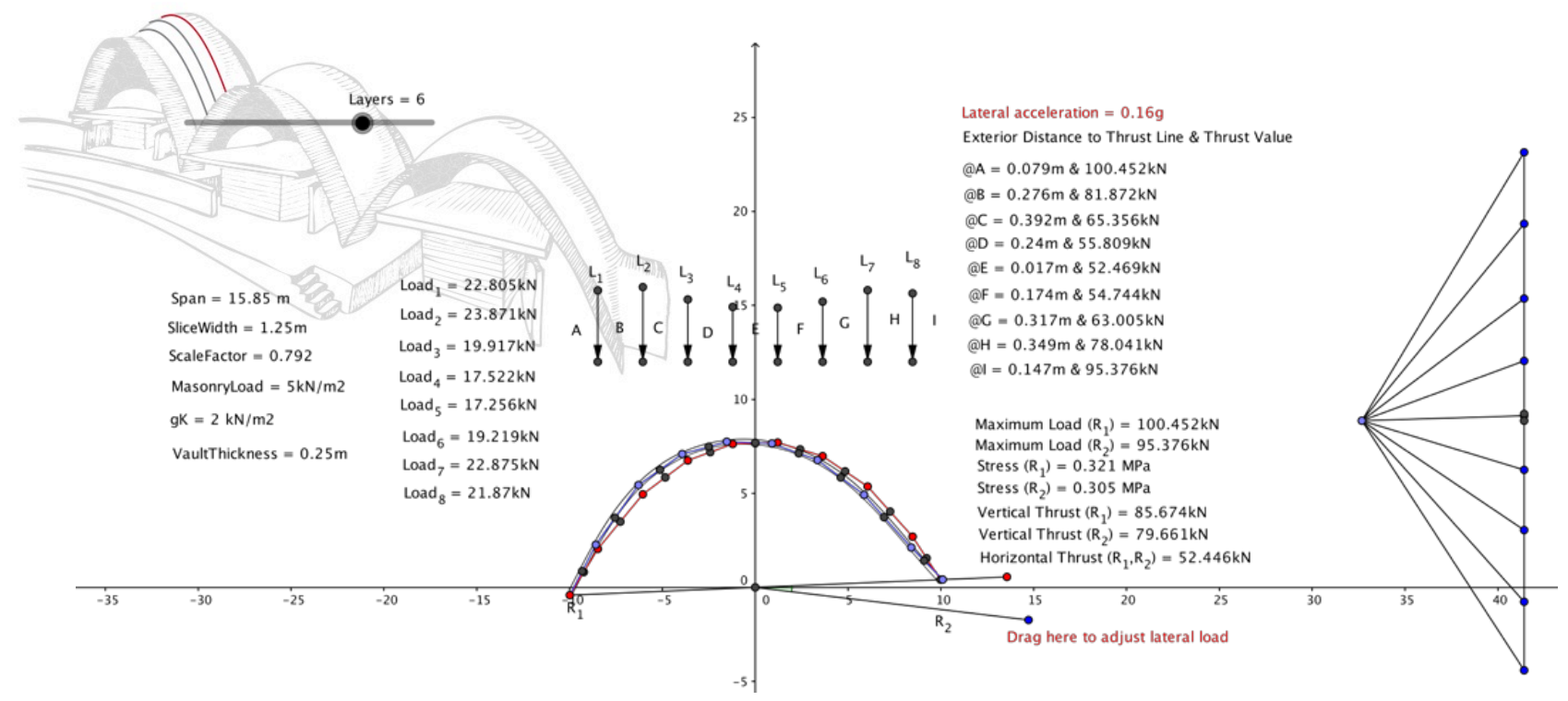

Figure 9 Line of thrust analysis with indicative cut and earthquake load case

We checked local buckling by considering a dome with radius equivalent to half of the maximum span from diagonally opposite corners. Each dome fully encloses a vault, has less curvature and greater span; thus the parabolic vaults will be less susceptible to buckling. We calculate critical buckling stress using

$$
\sigma_{c r}=0.2 E \frac{t}{r}
$$

from Ahm and Perry [10] and Heyman [11]. The modulus of elasticity (E) for compressed stabilized earth blocks can range by an order of magnitude from 0.7 to $7 \mathrm{GPa}$ [Houben and Guillaud 12], while that of mortar is significantly higher. The tiles used here have relatively high cement content $(10 \%)$ and are hydraulically pressed, so we estimate they are at the higher end of the range. Using $5 \mathrm{GPa}$ as $\mathrm{E}(\mathrm{t}=$ $250 \mathrm{~mm} ; \mathrm{r}=9600 \mathrm{~mm}$ ) results in a critical buckling stress of $13 \mathrm{MPa}$ on the largest dome; the highest stress in the vault is less than $0.35 \mathrm{MPa}$; in the load concentrated at the upper-most cross section vault the highest stress is $2.7 \mathrm{MPa}$.

Under static loads, the geometry and the thrust line coincide with the structure acting in compression. Under wind or earthquake loads, the thrust line deviates from the geometry, forcing it to rely on the tensile capacity of the geogrid, which defines a thrust envelope beyond the geometry [1]. Using the tensile properties of geogrid, the amount of geogrid needed to capture dynamic loads in the case of an earthquake or strong winds was calculated.

\section{Materials and Construction}

The building is formed by three doubly curved vaults with springing points at different heights and joined through arches. The biggest vault has a span of $16 \mathrm{~m}$ and a height of almost $8 \mathrm{~m}$. The vaults follow thrust lines and so are thin in comparison with their spans -thickness to radius ratio is $\sim 2 \%$. The biggest vault has a thickness of $250 \mathrm{~mm}$ : 6 layers of $25 \mathrm{~mm}$ compressed soil-cement tiles and $20 \mathrm{~mm}$ mortar beds between each layer. Each vault has 2 layers of geogrid sandwiched between the top and bottom outermost tile layers to provide dynamic stability in the case of an earthquake. Because the two end arches are critical areas if lateral loads arise parallel to their span, we placed a layer of geogrid in between each layer of tiles. To ensure the reinforced spans were anchored to the ground in the event of an earthquake, we placed a layer of geogrid between each layer of tiles and extend it $1 \mathrm{~m}$ into the concrete 


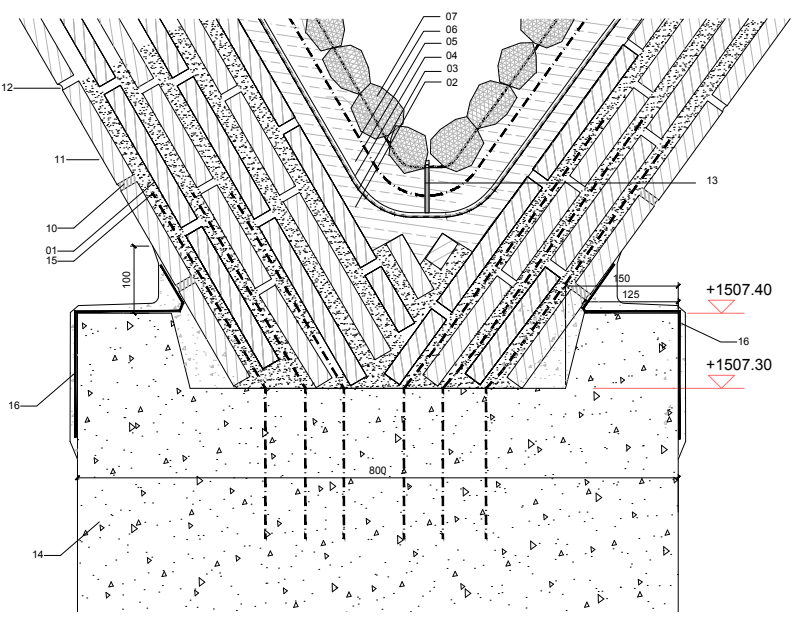

Figure 10 Detail (l) and construction (r) of vault-pier interface

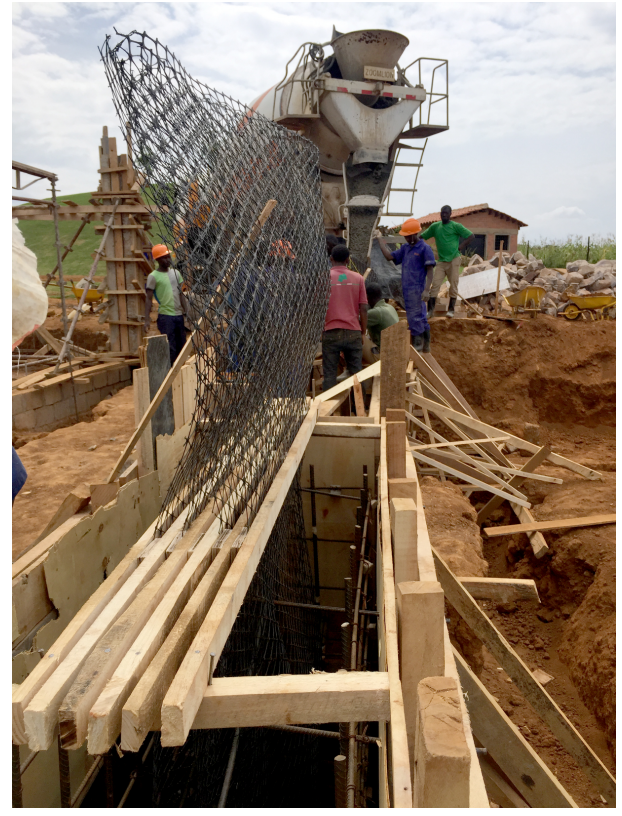

of each springing pier (Figure 10).

The formwork for building the arches and guidework for building the vaults was designed with Rhino and Grasshopper [13] in sizes that could fit the standard dimensions of plywood boards to use minimum material.

The vaults are covered by a $25 \mathrm{~mm}$ bonded cement-lime screed, waterproofed with bitumen primer and a torched-on membrane, covered with a $60 \mathrm{~mm}$ floating screed, reinforced with geogrid and topped with local stones to provide additional weight and further stability to the structure.

The project uses local and natural materials for the vaults, walls and flooring and reuses plywood and timber used for formwork and guides for doors, furniture and joinery. The project supports Rwanda's transition from an agriculture-based economy to development using local home-grown labor-intensive construction techniques, thereby avoiding imports, lowering carbon, and building skills and economies.

The vault construction used a mix of low-skilled and unskilled worker teams. The teams were trained by James Bellamy, an expert mason. One of the main goals of this project was to transfer the technology of thin-tile vaulting, unusual in East Africa, to local labour. There are further potential projects in the region to make use of the skills gained on this project. After the construction of the three vaults, followup sessions were conducted with masons and site engineers to discuss other applications and typologies.
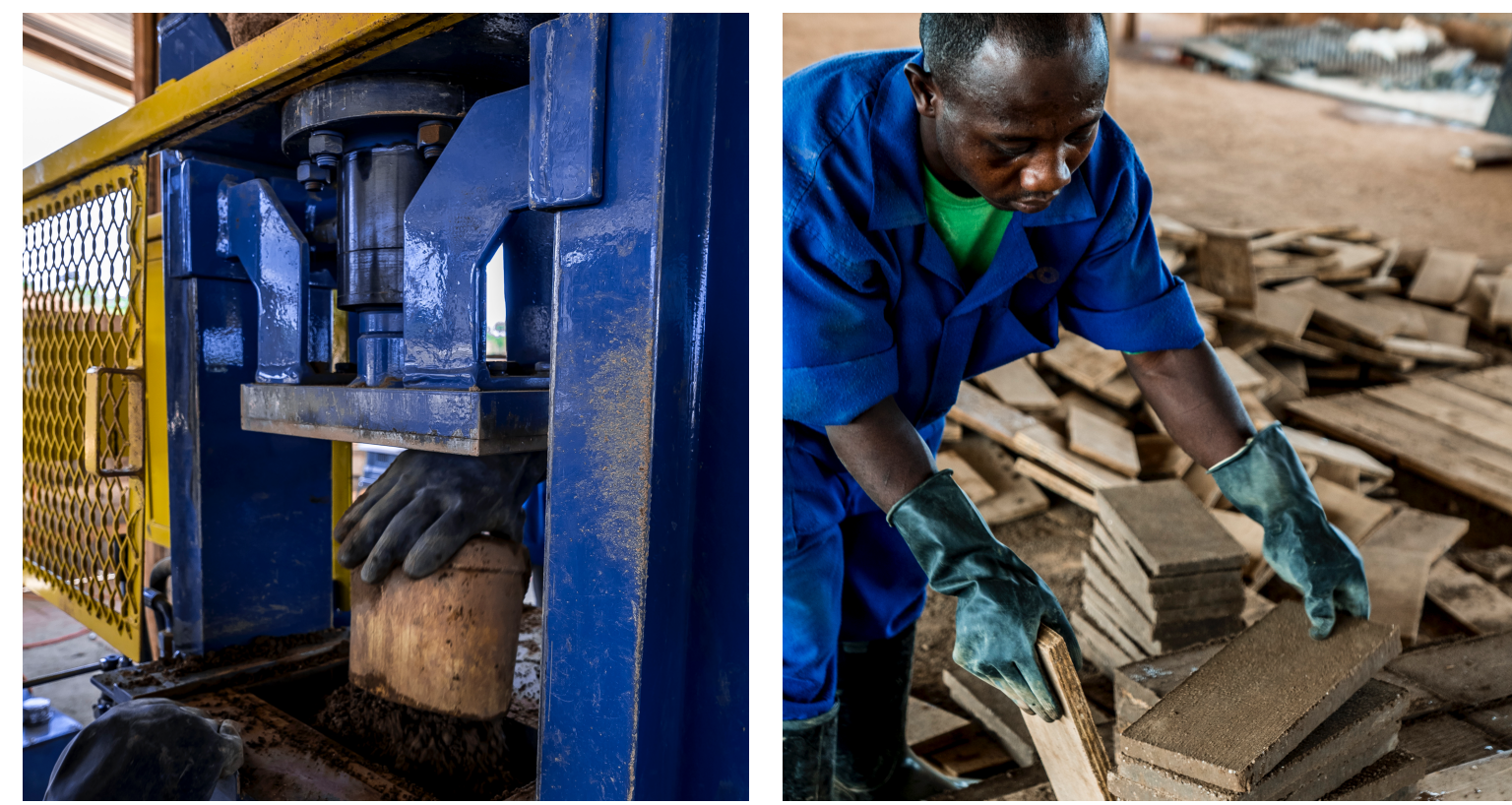

Figure 11 Making soil cement tiles 
The first phase of construction was making tiles with site-excavated soil and pressed with hydraulic presses. Hydraulic presses ensured greater consistency and higher quality tiles than experienced on previous projects that used only hand-pressed tiles (Figure 11). Tiles were made with $10 \%$ cement by volume; this was twice the amount specified, and the tiles were twice as strong as specified, but due to time constraints the client did not wish to reduce the amount. Future projects could reduce the amount of cement to 5\%, saving further cost and emissions. Tiles were also tested to ensure strength and quality, and could withstand stresses of up to $11 \mathrm{MPa}$, more than three times the maximum stresses in the shells. It took 43 days to produce 67000 tiles. The soil tiles are air cured with no firing to reduce the embodied energy of the building when compared to common construction methods currently used in Rwanda.

The project has been an opportunity to use bio-waste fired modern bricks and floor clay tiles from kilns recently modernised through the PROECCO programme supported by the Swiss Agency for Development and Cooperation (SDC) and implemented by the Swiss Resource Centre and Consultancies for Development (SKAT) [15]. These bricks and tiles are fired by rice husk, a carbon neutral bio-waste, we can therefore consider the production of these fired clay products as zero carbon. In comparison we have estimated the embodied carbon for the production of a traditional Rwandan brick at $0.78 \mathrm{kgCCO} 2 \mathrm{e} / \mathrm{kg}$, based on information by SKAT on traditional Rwandan Kilns and the inventory of Carbon and Energy [14]. For the production of a standard ceramic tile, the average figure from ICE is $0.70 \mathrm{kgCCO} 2 \mathrm{e} / \mathrm{kg}$.

There are approximately $345 \mathrm{~m}^{2}$ of brick walls on the project for a total of 23,000 bricks used; we estimate a savings of approximately 41 tons of $\mathrm{CO}_{2}$ emissions by using these bricks instead of traditional Rwandan bricks. Likewise, we have laid $310 \mathrm{~m}^{2}$ of bio-waste-fired clay floor tiles, saving a further 4 tons of $\mathrm{CO}_{2}$ emissions in comparison with typical ceramic tiles.

The second phase was building the guidework so the newly trained masons were able to visualize the shape of the vaults. Full formwork was made for the construction of the edge arches, with triangular pieces that describe the curved intersection between the vault surfaces and the arches. In another departure from tradition, because the arches would be in contact with rain water, the first layer of tiles was laid with white cement instead of fast-setting gypsum mortar as the latter is soluble in water. The guides and formwork were cut and assembled by local carpenters (Figure 12).
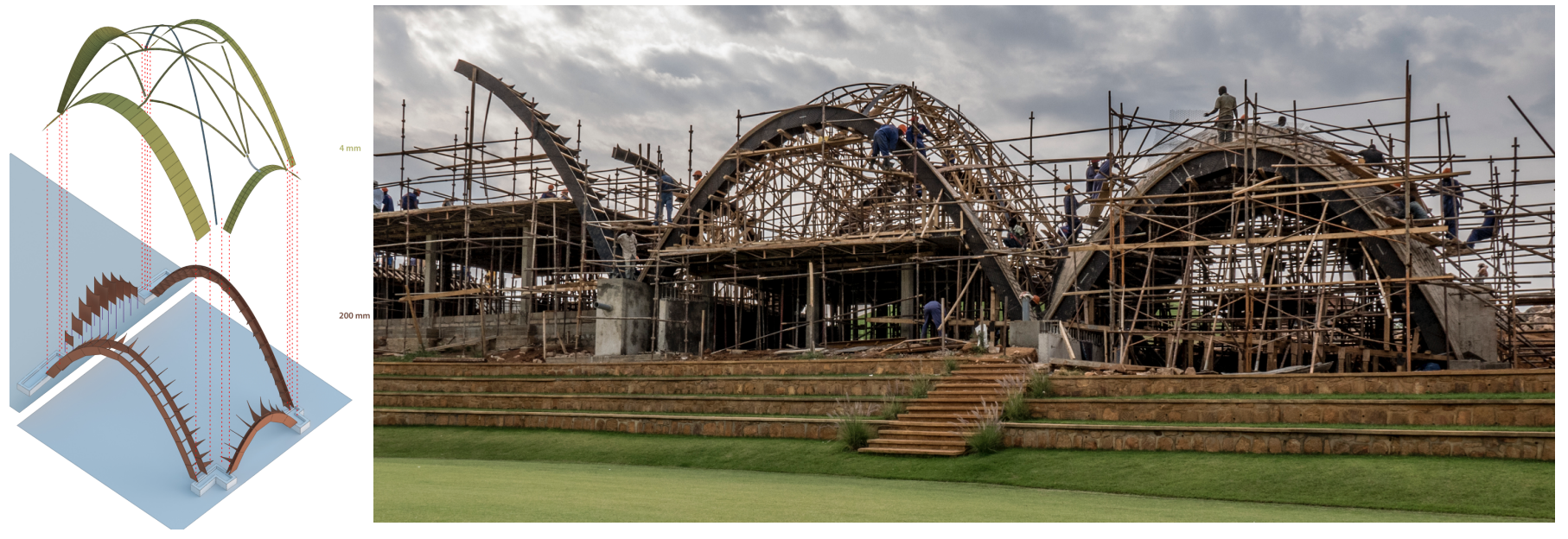

Figure 12 Formwork layout (1) and vaults under construction (r)

After a week of training local skilled and unskilled masons, the vaults were built. The vaults took 3 months with 39 masons, 25 porters and 10 scaffolders. The construction of the entire building took only 6 months in a highly accelerated program. Costs, when normalized for a standard program, are estimated at $\$ 200 / \mathrm{m}^{2}$ for the vaults, including all materials and labor for the structural spans, including a finished interior surface, but excluding waterproofing and covering. This is roughly equivalent to the vaults built at Mapungubwe in South Africa $\left(\sim \$ 130 / \mathrm{m}^{2}\right.$ in 2010 ; inflation in South Africa since then would be $\$ 190$ in equivalent 2017 dollars) and more than half the cost of building in the UK (Ramage et al [16]). It remains cost-effective in the land-locked Rwanda, where large-span concrete would cost at least $\$ 250$ $300 / \mathrm{m}^{2}$ and would result neither in a finished interior surface nor an expressive structure. 


\section{Conclusion}

The Rwanda Cricket Stadium (Figure 8) demonstrates an achievement on structural design and efficiency, sustainability and social impact. It grows from a long path of experimentation and research adapting an ancient technique using soil-cement tiles with lower embodied energy and geogrid for a moderate earthquake risk zone. It has proved to be a cost efficient and rapidly executable building method. Its design and analysis are based on the use of equilibrium methods to arrive to a structure acting purely in compression. The project celebrates natural, handmade and human elegance, but with large spans using a minimum of material, it demonstrates extreme structural efficiency and dynamic design.

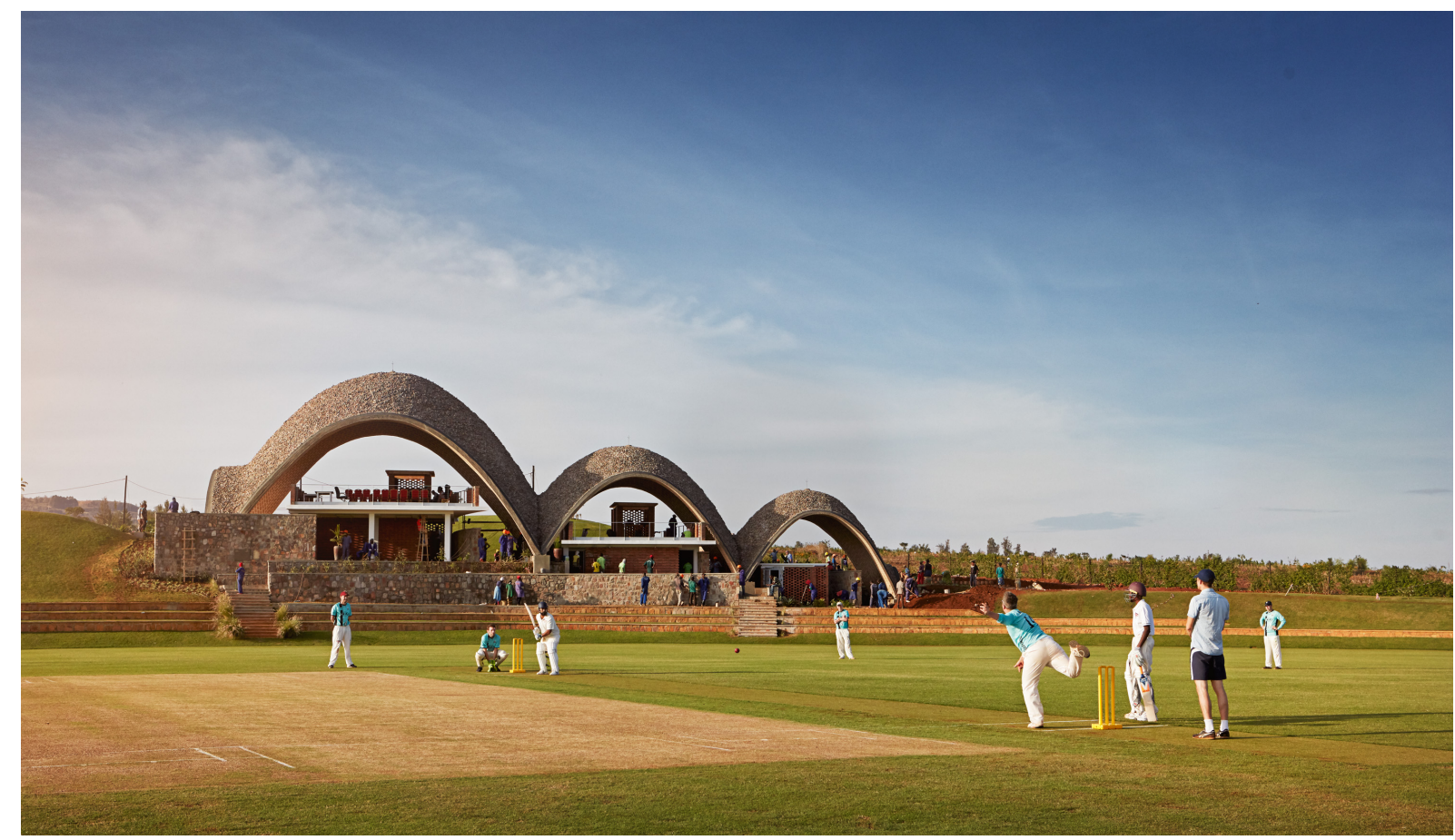

Figure 13 Rwanda Cricket Stadium $@$ Jonathan Gregson; used with permission

\section{Acknowledgements}

T Hall led the project, M Ramage and A Gatóo conducted the structural design and analysis, and W Al Asali designed the formwork and investigated the impact of the vaulting on the workforce. The authors are grateful to the Rwanda Cricket Stadium Foundation, to J Bellamy, who trained and oversaw vault construction, to B Veyrac, and to our colleagues at Pan Mixers South Africa (tile presses), FBW Ltd (civil engineers) and Roko Ltd (contractors). WA received funding from Clare Hall, Cambridge.

\section{References}

[1] M.H. Ramage and M.J. Dejong, "Design and Construction of Geogrid-reinforced Thin-shell Masonry" in Taller, Longer, Lighter:, eds D. A. Nethercot and S. Pellegrino. IASS London 2011.

[2] M.H Ramage, J. Ochsendorf, and P. Rich, "Sustainable Shells: New African vaults built with soilcement tiles," Journal of the International Association of Shell and Spatial Structures, vol. 51, no. pp 255-261, 2010.

[3] J. Ochsendorf, Guastavino Vaulting: The Art of Structural Tile. Princeton Architectural Press, New York, 2010

[4] Tensar TX, TriAx Inc. 
[5] M.J. DeJong, M.H. Ramage, B. Travers, S. Terry, "Testing and Analysis of Geogrid-reinforced Thin-shell Masonry" in Taller, Longer, Lighter:, eds D. A. Nethercot and S. Pellegrino. IASS London 2011.

[6] E. Allen and W. Zalewski, Form and Forces:Designing Efficient, Expressive Structures, John Wiley \& Sons, New York, 2009.

[7] T. Van Mele, L. Lachauer, M. Rippmann, P. Block, "Geometry-based understanding of structures." Journal of the International Association of Shell and Spatial Structures, 2012.

[8] P. Block, M.J. DeJong, J. Ochsendorf, As Hangs the Flexible Line: Equilibrium of Masonry Arches, Nexus Network Journal, Vol. 8, No. 2, pp 13-24, 2006.

[9] www.geogebra.org

[10] P. Ahm and E. Perry, Design of the Dome Shell Roof for Smithfield Poultry Market, Proceedings of the Institution of Civil Engineers, 30, 79 pp 79-108, 1965.

[11] J. Heyman, On Shell Solutions for Masonry Domes, International Journal of Solids and Structures, vol 3 pp 227-241, 1967.

[12] H. Houben and H. Guillaud, Earth Construction: A Comprehensive Guide. Intermediate Technology Publications, London, UK, 1994.

[13] www.rhino3d.com

[14] G.P. Hammond, and C.I. Jones, Embodied energy and carbon in construction materials. Proceedings of the Institution of Civil Engineers - Energy, 161 (2), pp. 87-98, 2008.

[15] http://skat.ch/portfolio-item/the-proecco-programme/ accessed 28/04/2018.

[16] M.H. Ramage, J. Ochsendorf, P. Rich, J.K. Bellamy, P. Block, "Design and Construction of the Mapungubwe National Park Interpretive Centre, South Africa," African Technology Development Forum Special Issue: Architecture and Development, October, pp 14-23, 2010. 